\title{
Carbohydrate Contribution to Fruit Development in Two Phenologically Distinct Rabbiteye Blueberry Cultivars
}

\author{
Rebecca L. Darnell and Keith B. Birkhold \\ Horticultural Sciences Department, University of Florida, Gainesville, FL 32611 \\ Additional index words. carbon reserves, partitioning, soluble sugars, source-sink, starch, Vaccinium ashei
}

\begin{abstract}
Rabbiteye blueberry (Vaccinium ashei Reade) cultivars differ in timing of floral and vegetative budbreak and in final fruit size. For example, 'Bonita' exhibits concomitant floral and vegetative budbreak and has relatively large fruit size, while floral budbreak precedes vegetative budbreak in 'Climax' and fruit size is smaller. Mobilization of carbohydrate before and during fruit development in 'Bonita' and 'Climax' rabbiteye blueberries was examined to determine if differences in carbohydrate availability between these two cultivars were correlated with differences in fruit size. Root dry mass (DM) of both cultivars decreased from dormancy (31 days before anthesis) through fruit development. Sugar concentrations in roots and stems of both cultivars decreased significantly between dormancy and anthesis, then remained relatively steady throughout fruit development. Starch concentrations in roots and stems of 'Bonita' decreased significantly between dormancy and anthesis. The extent of total starch depletion in 'Climax' was similar; however, the decrease was more gradual, extending from dormancy to 28 days after anthesis (DAA); at which time, vegetative budbreak in 'Climax' occurred. Thus, although total reserve carbohydrate pool sizes were similar between the two cultivars, remobilization patterns were different, resulting in increased starch mobilization in 'Bonita' compared to 'Climax' in the period leading up to anthesis. Concentration of ${ }^{14} \mathrm{C}$ from reserve carbon sources was similar in flowers of both cultivars at anthesis. These values declined throughout fruit development as a result of dilution of the labeled carbon by unlabeled carbon from current photosynthesis. There was a sharper decline in ${ }^{14} \mathrm{C}$ concentration of 'Bonita' fruit compared to 'Climax' fruit between anthesis and $51 \mathrm{DAA}$. This, coupled with differences in timing of vegetative budbreak between the two cultivars, suggests that 'Bonita' fruit were accessing current (unlabeled) assimilate earlier (i.e., before 51 DAA) than 'Climax' fruit. Smaller fruit size in 'Climax' compared to 'Bonita' may be a consequence of a decrease in reserve carbohydrate mobilization to 'Climax' flower buds before anthesis relative to 'Bonita', as well as a delay or reduction in the availability of current carbohydrates to developing 'Climax' fruit between anthesis and 51 DAA.
\end{abstract}

During the spring, deciduous perennial crops remobilize carbohydrate accumulated during the previous growing season to the current season's reproductive and vegetative growth. Before the export of photoassimilates from the current season's photosynthetic tissues, developing sink tissues must rely totally on reserve carbohydrate. Reserve carbohydrate, however, plays a less significant role once the new vegetative canopy begins exporting carbohydrate. The contribution of reserve and currently assimilated carbohydrate may vary depending on the rate at which the sinks deplete the plant reserves and the developmental sequence of vegetative and reproductive growth (Wardlaw, 1990). Rabbiteye blueberries differ in their timing of vegetative and reproductive growth depending on the cultivar and amount of chilling (Darnell and Davies, 1990). This difference may result in differences in the contribution from reserve vs. current carbohydrate pools to developing flowers, fruit, and new vegetative growth.

Labeling of plant reserve carbohydrate with ${ }^{14} \mathrm{C}$ has been used to distinguish between current and reserve carbohydrate sources in a variety of perennial plant species (Hansen, 1967, 1971; Kandiah, 1979b; Lockwood and Sparks, 1978a, 1978b; Quinlan and Preston, 1968). DM gain of the first five to six leaves in apple depend on reserve carbohydrate, with subsequent leaves receiving carbohy-

Received for publication 28 Feb. 1996. Accepted for publication 8 July 1996. University of Florida Journal Series no. R-05162. The cost of publishing this paper was defrayed in part by the payment of page charges. Under postal regulations, this paper therefore must be hereby marked advertisement solely to indicate this fact. drate from current assimilates (Hansen, 1971). Flower and early fruit development in apple also depend on carbohydrate reserves, although spur leaf photosynthesis supplies some of the imported carbohydrate (Quinlan and Preston, 1969). Similarly, reserve carbon is mobilized to first-formed leaves, shoots, and new roots in walnut (Lacointe et al., 1993) and pecan (Lockwood and Sparks, 1978a), as well as pistillate and staminate inflorescences in pecan (Lockwood and Sparks, 1978a).

Blueberry offers a system that allows further study of the role of reserve vs. currently assimilated carbohydrate in reproductive and vegetative growth. In rabbiteye blueberry, floral budbreak occurs either before or concomitant with vegetative budbreak, depending primarily on cultivar (Darnell and Davies, 1990). Thus, for some cultivars, there can be a relatively long period in early spring when fruit development must depend solely on reserve carbohydrate or fruit photosynthesis since there are no leaves present to contribute currently assimilated carbohydrate. Field observations and studies with containerized plants (Birkhold et al., 1992) indicate that fruit in these cultivars are usually markedly smaller than fruit in cultivars that exhibit concomitant floral and vegetative budbreak.

The following study compares differences in reserve carbohydrate usage between 'Bonita' and 'Climax' rabbiteye blueberry plants during flower bud and fruit development. 'Bonita' exhibits concomitant floral and vegetative budbreak, while floral budbreak precedes vegetative budbreak in 'Climax'. Furthermore, fruit size in 'Climax' is significantly smaller than that of 'Bonita', even when fruit numbers are similar (Birkhold et al., 1992). Our objective was to determine if differences in the availability of reserve and current carbohydrate were associated with differences 


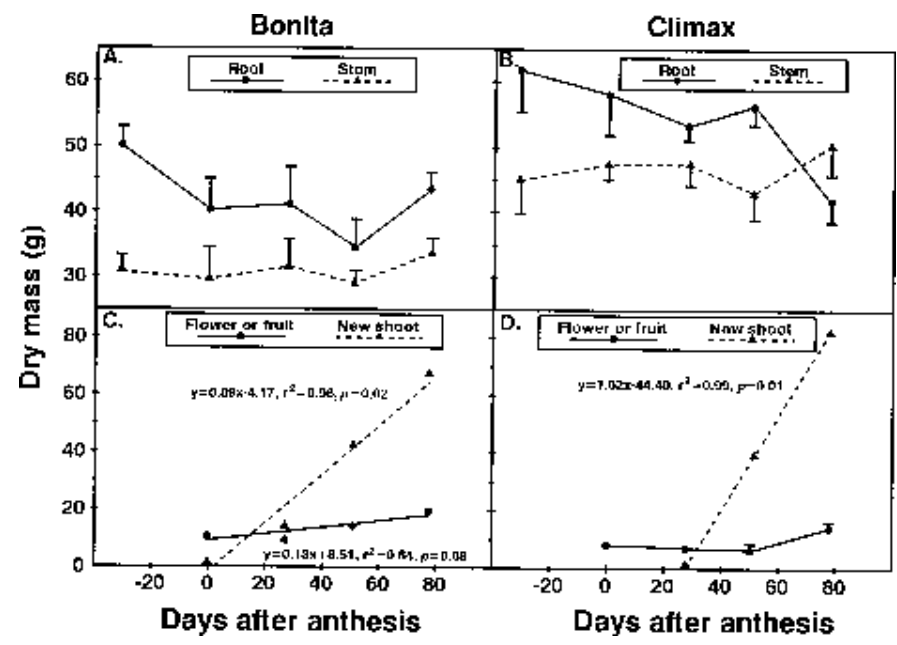

Fig. 1. Dry mass of rabbiteye blueberry plants between dormancy [ $-31 \mathrm{~d}$ after anthesis (DAA)] and fruit maturity (78 DAA): root and stem DM for (A) 'Bonita' and (B) 'Climax', flower and fruit and new shoot DM for (C) 'Bonita' and (D) 'Climax' (means $\pm \mathrm{SE}, \mathrm{n}=4$, SE bars present only when larger than symbol).

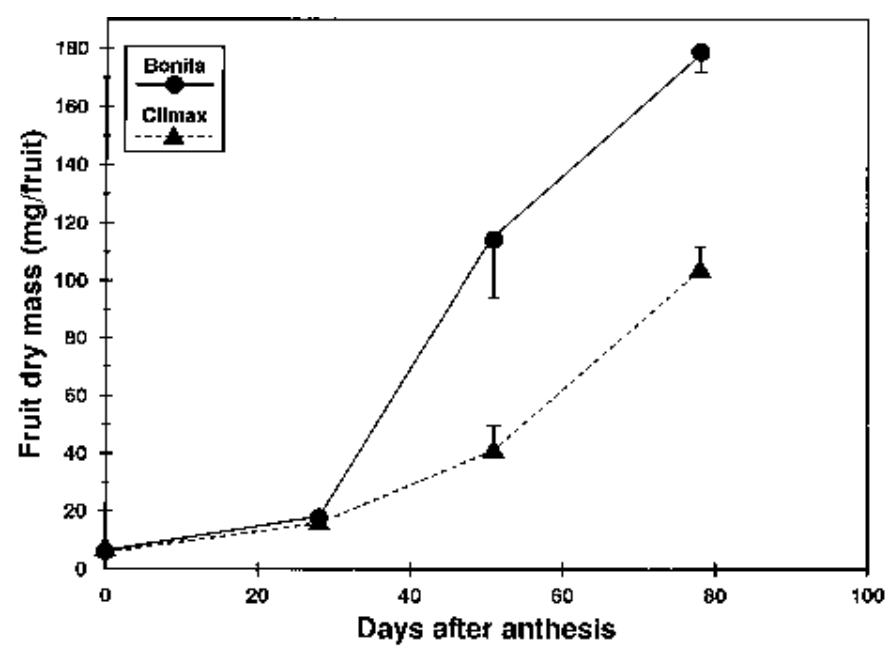

Fig. 2. Dry mass of 'Bonita' and 'Climax' rabbiteye blueberry fruit from anthesis to ripening (means $\pm \mathrm{SE}, \mathrm{n}=4$, SE bars present only when larger than symbol).

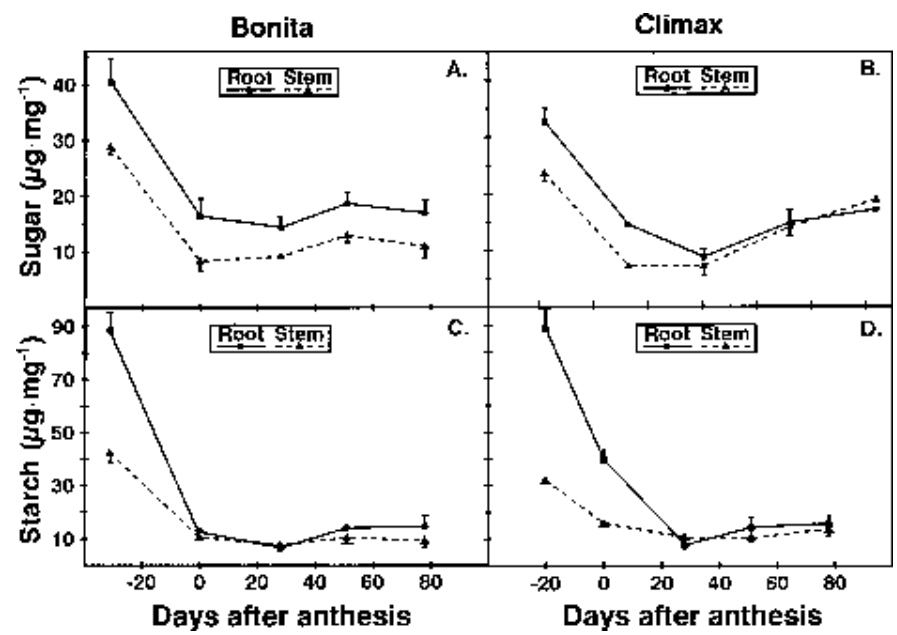

Fig. 3. (A and B) Sugar and (C and D) starch concentrations (dry-mass basis) in roots and stems of (A and $\mathbf{C})$ 'Bonita' and (B and $\mathbf{D})$ 'Climax' rabbiteye blueberry plants between dormancy [-31 d after anthesis (DAA)] and fruit maturity (78 DAA) (means \pm SE, $n=4$, sE bars present only when larger than symbol). in fruit size in these cultivars. Additionally, the changes in total sugars and starch in stems and roots were determined to assess the importance of these carbohydrate storage forms to spring growth.

\section{Materials and Methods}

Plant material. 'Bonita' and 'Climax' rabbiteye blueberry plants were propagated by softwood cuttings in May 1988 and were field-grown from June 1988 until Feb. 1989. Twenty plants of each cultivar were removed from the field, planted into 22-L pots containing a 1 peat : 1 pine bark mix, pruned to one main stem, and maintained outdoors from Feb. 1989 until plant harvest the following year. During the 1989 growing season, plants were watered as needed and fertilized with water-soluble fertilizer $(20 \mathrm{~N}-6.1 \mathrm{P}-11.6 \mathrm{~K})$ at $3.5 \mathrm{~g} \cdot \mathrm{L}^{-1}$ (Peters, Scott-Sierra Horticultural Products Co., Marysville, Ohio) every 2 weeks through July and every 3 weeks from August through mid-September when fertilization was stopped. Fertilization at the same rate resumed at anthesis the following spring.

${ }^{14} \mathrm{C}$ labeling. To trace reserve carbohydrate, ${ }^{14} \mathrm{CO}_{2}$ was supplied to the plants on 3 and 17 Oct. and 7 Nov. 1989. On each labeling date, plants were moved into the greenhouse, all shoots were enclosed in a $48 \times 60$-cm clear bag, and ${ }^{14} \mathrm{CO}_{2}$ was generated by reacting $1.30 \mathrm{MBq}$ of ${ }^{14} \mathrm{C}-\mathrm{NaHCO}_{3}$ (s.a., $2.16 \mathrm{GBq} \cdot \mathrm{mmol}^{-1}$ ) with $70 \mu \mathrm{L} 10 \% \mathrm{H}_{2} \mathrm{SO}_{4}$ inside an eppendorf tube within the bag. After $1 \mathrm{~h}$, bags were removed and plants were moved outside until the next labeling period. The photosynthetic photon flux within the greenhouse during the labeling periods ranged from 500 to 1200 $\mu \mathrm{mol} \cdot \mathrm{m}^{-2} \cdot \mathrm{s}^{-1}$, and air temperature ranged from 20 to $25^{\circ} \mathrm{C}$.

Plant harvest and handling. Four individual plant replicates from each cultivar were randomly selected and harvested at each of five dates in 1990. Leaves that dropped during the fall and winter were collected by encircling each plant with wire mesh. The initial harvest was during dormancy ( 2 Feb., $31 \mathrm{~d}$ pre-anthesis), with the second harvest occurring when $80 \%$ of the plants reached $\approx 80 \%$ anthesis (9 Mar. for both cultivars). The third harvest was $28 \mathrm{~d}$ after anthesis (DAA) (6 Apr.), when most of the fruit drop occurred and shoot growth differences between cultivars were manifested. At this time, the vegetative canopy of 'Bonita' was well established, while 'Climax' leaf buds were just beginning to break. In the double sigmoid fruit growth pattern established earlier for these two cultivars (Birkhold et al., 1992), 28 DAA is midway through stage I of fruit growth. By the fourth harvest (29 Apr., 51 DAA), both cultivars had well-established vegetative canopies and stage III of fruit development was beginning (Birkhold et al., 1992). The final harvest was at fruit maturity (26 May, 78 DAA). At each harvest, plants were divided into roots, stems (produced during the previous growing season), flowers or fruit, and new shoot growth. Flowers and fruit that abscised were not collected for analysis. Roots and stems formed during 1988 and 1989 contained the labeled reserves used for the 1990 vegetative and reproductive growth. Flowers or fruit on an individual plant were counted, combined, and treated as a single tissue sample. Plant roots were separated from the growth media by rinsing roots in water. Although some small roots were lost via this procedure, most roots containing the labeled reserves were recovered. Following fresh mass measurements of all plant parts, tissues were freeze-dried, weighed, ground through a 40 mesh $\left(\approx 0.5 \mathrm{~mm}^{2}\right)$ screen in a Wiley mill, and stored in sealed plastic bags. Individual fruit DM was calculated using total fruit DM per plant and fruit count.

Carbohydrate analysis. Root and stem soluble sugars were determined by extracting $50 \mathrm{mg}$ of dried, ground tissue in boiling $80 \%$ ethanol $(1: 100 \mathrm{w} / \mathrm{v})$ for $2 \mathrm{~min}$. Extracts were shaken for 20 
min and centrifuged, and the supernatant was decanted. The remaining pellet was re-extracted twice. The supernatants were combined, and final volumes were measured. Aliquots of the final volumes were analyzed for total soluble sugars. Percentage recovery was estimated using ${ }^{14} \mathrm{C}$-sucrose as an external standard. Sugar concentrations were quantified by the phenol-sulfuric acid colorimetric procedure (Chaplin and Kennedy, 1986), with sucrose as the standard and corrected for percent recovery.

Stem and root starch content was determined as previously described (Darnell, 1991). Briefly, the $80 \%$ ethanol-insoluble pellet was suspended in $2.0 \mathrm{~mL}$ of $0.2 \mathrm{~N} \mathrm{KOH}$ and boiled for $30 \mathrm{~min}$. After cooling, the $\mathrm{pH}$ was adjusted to 4.5 with $1.0 \mathrm{~mL}$ of $1 \mathrm{M}$ acetic acid and $1.0 \mathrm{~mL} 0.2 \mathrm{~m}$ calcium acetate buffer ( $\mathrm{pH} 4.5)$, containing $9 \mathrm{mg} \cdot \mathrm{mL}^{-1}$ Rhizopus amyloglucosidase (Sigma, St. Louis), was added. Samples were shaken at $37^{\circ} \mathrm{C}$ for $24 \mathrm{~h}$. Following incubation, sample pigment was removed by adding $75 \mathrm{mg}$ activated charcoal, and the glucose liberated from starch hydrolysis was quantified by the phenol-sulfuric acid method.

Concentrations of ${ }^{14} \mathrm{C}$ in the different tissues were determined by solubilizing $5 \mathrm{mg}$ of dried plant tissue in $500 \mu \mathrm{L}$ of TS-1 (Research Products International Corp., Prospect, Ill.), and incubating the samples for $24 \mathrm{~h}$ at $60{ }^{\circ} \mathrm{C}$. Chemiluminescence was eliminated by adding $15 \mathrm{~mL}$ of scintillation fluid containing $5 \%$ acetic acid, and ${ }^{14} \mathrm{C}$ was determined by liquid scintillation spectroscopy. Total ${ }^{14} \mathrm{C}$ in new shoot growth and individual fruit was calculated using ${ }^{14} \mathrm{C}$ concentrations and DM data.

\section{Results}

Plant development. Changes in root and stem DM of 'Bonita' and 'Climax' plants could not be appropriately modeled by regression analysis. Root DM of 'Bonita' decreased from 50 to $40 \mathrm{~g}$ between dormancy (31 d pre-anthesis, or -31 DAA) and bloom ( 0 DAA) and remained relatively steady throughout the rest of the fruit development period (Fig. 1A). Very little change occurred in DM of 'Bonita' stems. There was little change in root DM of 'Climax' from dormancy to 51 DAA (Fig. 1B), but root DM decreased significantly during the final stage of fruit development. DM of 'Climax' stems remained relatively stable throughout the fruit development period.

Spring shoot growth of 'Bonita' began concomitantly with floral budbreak, and growth increased linearly between anthesis and fruit maturity (78 DAA) (Fig. 1C). Total new shoot DM at fruit maturity averaged $70 \mathrm{~g} /$ plant. Total flower and fruit DM increased linearly from $\approx 10 \mathrm{~g} /$ plant at anthesis to $\approx 20 \mathrm{~g} / \mathrm{plant}$ by fruit maturity. DM accumulation per fruit in 'Bonita' was slow between 0 and 28 DAA, then increased sharply between 28 DAA and fruit maturity (Fig. 2). The sampling times used in this experiment were too few to show the double sigmoid fruit growth pattern previously observed (Birkhold et al., 1992). 'Bonita' plants averaged $\approx 1600$ florets per plant at anthesis. Between 0 and 51 DAA, flowers and fruit abscised, after which fruit count remained stable. By fruit maturity, 'Bonita' plants averaged 110 fruit per plant.

Vegetative budbreak of 'Climax' began $\approx 28$ DAA, and new shoot DM increased linearly throughout fruit development (Fig. 1D). By fruit maturity, shoot DM averaged $80 \mathrm{~g} /$ plant. There was little change in total flower or fruit DM throughout early to middevelopment, with a slight but significant increase during the final stage of fruit development. On an individual fruit basis, 'Climax' fruit exhibited a slow increase in DM between anthesis and 51 DAA, followed by a faster increase between 51 and 78 DAA (Fig. 2). 'Climax' plants averaged 1300 florets per plant at anthesis. Following the wave of abscission between 0 and 28 DAA, fruit number stabilized, and by fruit maturity, 'Climax' plants averaged 140 fruit per plant. There were no significant differences in fruit number between 'Bonita' and 'Climax' plants at any stage of development.

Carbohydrates. There was a significant decrease in soluble sugar concentration in roots and stems of 'Bonita' plants between dormancy and anthesis (Fig. 3A). Sugar concentrations decreased from $\approx 40$ to $15 \mu \mathrm{g} \cdot \mathrm{mg}^{-1} \mathrm{DM}$ and from $\approx 30$ to $10 \mu \mathrm{g} \cdot \mathrm{mg}^{-1} \mathrm{DM}$ in the roots and stems, respectively. There were no further changes in root or stem sugar concentrations following anthesis. Sugar concentrations in 'Climax' roots and stems displayed a pattern similar to 'Bonita' (Fig. 3B). Root sugar concentrations decreased from $\approx 30$ to $10 \mu \mathrm{g} \cdot \mathrm{mg}^{-1} \mathrm{DM}$ between dormancy and $28 \mathrm{DAA}$, then increased slightly. Stem sugar concentrations decreased from $\approx 25$ to $10 \mu \mathrm{g} \cdot \mathrm{mg}^{-1} \mathrm{DM}$ between dormancy and anthesis before increasing to $\approx 20 \mu \mathrm{g} \cdot \mathrm{mg}^{-1} \mathrm{DM}$ at fruit maturity. Total sugar content (Fig. $4 \mathrm{~A}$ and $\mathrm{B}$ ) in roots and stems of both cultivars exhibited patterns of depletion similar to sugar concentrations (Fig. 3 A and B).

Starch concentrations in roots of 'Bonita' and 'Climax' decreased dramatically but in temporally different ways. Root starch concentrations in 'Bonita' decreased from $\approx 90$ to $15 \mu \mathrm{g} \cdot \mathrm{mg}^{-1} \mathrm{DM}$ between dormancy and anthesis (Fig. 3C). The extent of total starch depletion in 'Climax' roots was similar (Fig. 3D); however, the decrease was more gradual, extending from dormancy to vegetative budbreak (28 DAA). At anthesis, there was a 3-fold greater starch concentration in 'Climax' roots than in 'Bonita' roots. The patterns of stem starch concentration depletion were similar to those displayed by roots of each cultivar, although changes were not as dramatic. Total root and stem starch content (Fig. 4C and D) in both cultivars showed depletion patterns similar to starch concentrations (Fig. $3 \mathrm{C}$ and D).

Accumulation of ${ }^{14} \mathrm{C}$. Concentration of ${ }^{14} \mathrm{C}$ from reserve carbon sources was relatively high and similar in flowers of both cultivars at anthesis, averaging 5.0 and 5.6 Bq. $\mathrm{mg}^{-1} \mathrm{DM}$ for 'Bonita' and 'Climax', respectively (Fig. 5A). These values declined dramatically throughout the fruit development period for both cultivars as a result of dilution of the labeled carbon by unlabeled carbon, presumably from current photosynthesis. By fruit maturity, ${ }^{14} \mathrm{C}$ concentration in fruit of both cultivars averaged $\approx 0.3 \mathrm{~Bq} \cdot \mathrm{mg}^{-1} \mathrm{DM}$. There was a sharper decline in ${ }^{14} \mathrm{C}$ concentration of 'Bonita' fruit compared to 'Climax' fruit between anthesis and 51 DAA. Total ${ }^{14} \mathrm{C}$ accumulation in 'Bonita' fruit increased from $\approx 35$ to $80 \mathrm{~Bq} /$ fruit between 28 and 51 DAA before declining to $\approx 40 \mathrm{~Bq} /$ fruit at fruit maturity (Fig. 6A). Total ${ }^{14} \mathrm{C}$ accumulation in 'Climax' fruit was similar through $51 \mathrm{DAA}$, averaging $\approx 50 \mathrm{~Bq} /$ fruit. Between 51 and $78 \mathrm{DAA}$, total ${ }^{14} \mathrm{C}$ in fruit increased to $\approx 80 \mathrm{~Bq}$. Individual 'Climax' fruit contained significantly more ${ }^{14} \mathrm{C}$ than individual 'Bonita' fruit at 28 DAA and fruit maturity (78 DAA).

In new shoot growth of both cultivars, ${ }^{14} \mathrm{C}$ concentration decreased in a manner similar to that in fruit, again as a result of dilution of the labeled carbon by unlabeled carbon presumably from current photosynthesis (Fig. 5B). Total ${ }^{14} \mathrm{C}$ accumulation increased in new shoot growth of 'Bonita' between anthesis and 28 DAA (Fig. 6B), with no significant change thereafter. At fruit maturity (78 DAA), total ${ }^{14} \mathrm{C}$ accumulation in 'Bonita' shoots was not significantly less than at 28 or 51 DAA $(P>0.05)$. In 'Climax' new shoot growth, ${ }^{14} \mathrm{C}$ accumulation increased between 28 and 51 DAA and then remained steady through fruit maturity. There were no differences in total ${ }^{14} \mathrm{C}$ accumulation in new shoot growth between the two cultivars when vegetative stages were compared phenologically. For example, at vegetative budbreak (0 DAA for 'Bonita' and 28 DAA for 'Climax'), total ${ }^{14} \mathrm{C}$ accumulation in new shoot growth of both cultivars averaged $\approx 1.8 \mathrm{kBq}$. 
Bonita

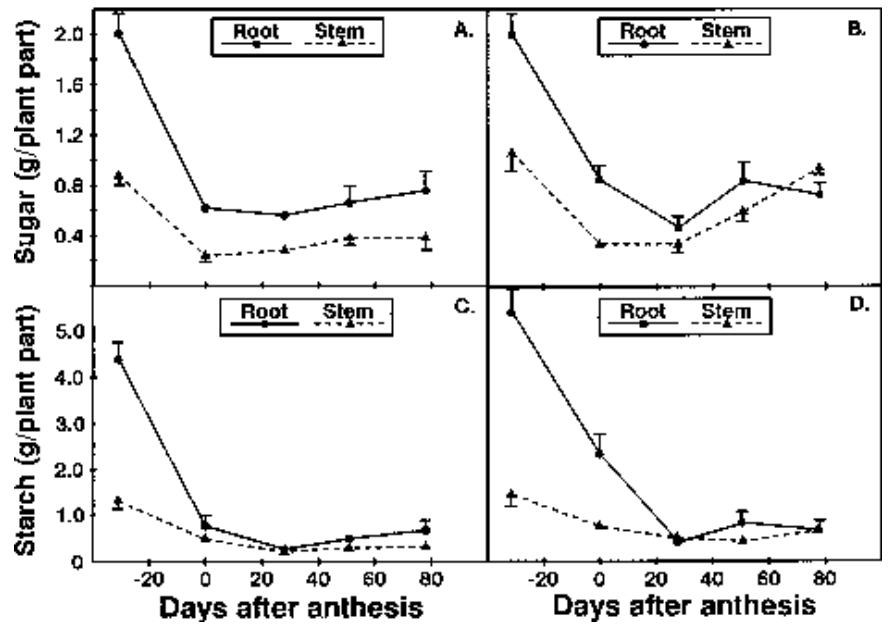

Fig. 4. (A and $\mathbf{B})$ Sugar and (C and $\mathbf{D})$ starch content in roots and stems of (A and C) 'Bonita' and (B and D) 'Climax' rabbiteye blueberry plants between dormancy $[-31 \mathrm{~d}$ after anthesis (DAA)] and fruit maturity (78 DAA) (means $\pm \mathrm{sE}, \mathrm{n}$ $=4$, SE bars present only when larger than symbol).

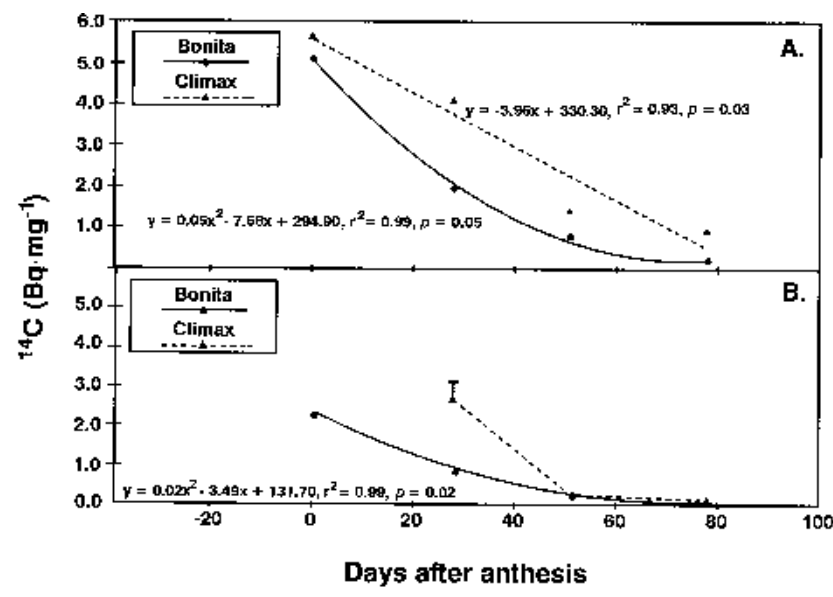

Fig. 5. Concentration of ${ }^{14} \mathrm{C}$ (dry-mass basis) in (A) flowers and fruit and (B) new shoot growth of 'Bonita' and 'Climax' rabbiteye blueberry plants between anthesis and fruit maturity ( $78 \mathrm{~d}$ after anthesis) (means $\pm \mathrm{SE}, \mathrm{n}=4$, SE bars present only when larger than symbol).

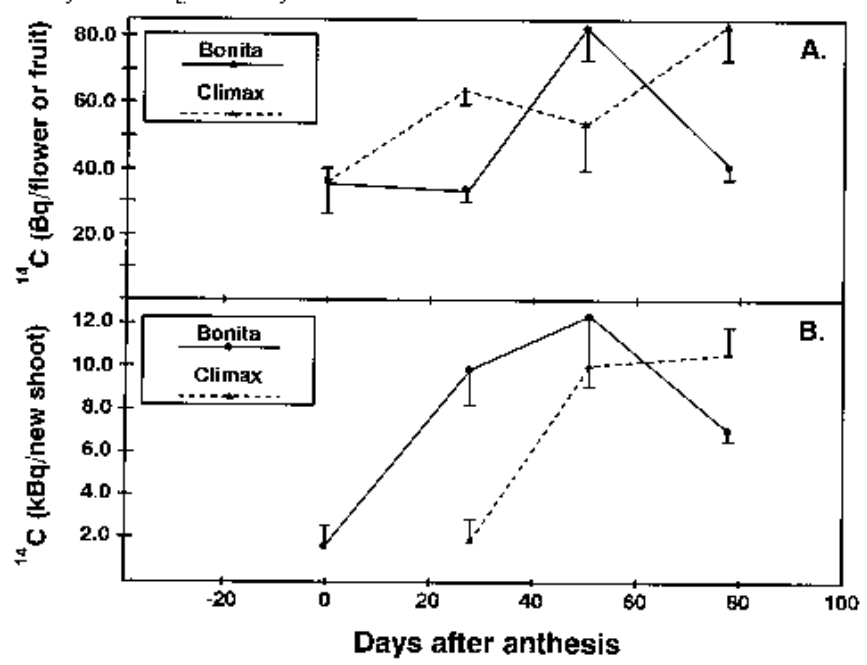

Fig. 6. Accumulation of ${ }^{14} \mathrm{C}$ in (A) flowers and fruit and (B) new shoot growth of 'Bonita' and 'Climax' rabbiteye blueberry plants between anthesis and fruit maturity ( $78 \mathrm{~d}$ after anthesis ) (means $\pm \mathrm{SE}, \mathrm{n}=4$, SE bars present only when larger than symbol).

\section{Discussion}

Losses in root DM during fruit development have been observed in several fruit crops (Kandiah, 1979a; Quinlan, 1969) and suggest that carbohydrate was being remobilized to new growth during this time. This is substantiated by the decline in root and stem carbohydrate concentrations during bloom and early fruit development. The most rapid decline in carbohydrate concentration in roots and stems of 'Bonita' occurred between dormancy (-31 DAA) and anthesis (0 DAA). Calculation of total carbohydrate content on a plant-part basis reveals that the decrease in root starch and sugar levels accounts for $>70 \%$ of the decrease in DM in 'Bonita' roots. Carbohydrate content in 'Bonita' stems also decreased by $\approx 3 \mathrm{~g}$ during this same period. This decrease was not apparent as a DM loss in stems. This may be because the decrease was too small to be measured or that any decrease in stem DM was compensated for by remobilization of carbohydrate from the roots.

Depletion of stem and root carbohydrate during early spring growth of perennial fruit crops to support growth of new vegetative and reproductive organs has been well documented. In apple and peach, stem and root carbohydrate decline significantly during the first 8 weeks after budbreak. Soon thereafter, while fruit are still on the tree, replenishment of these carbohydrate pools begins (Oliveira and Priestley, 1988; Stassen et al., 1981). In contrast, replenishment of nonstructural carbohydrate in current season shoots and roots of sweet cherry does not begin until after fruit harvest (Keller and Loescher, 1989). This is apparently the case in blueberry as well and is probably related to the high demand for carbohydrate elicited by concomitant fruit and shoot growth and the short fruit development period.

Root carbohydrate levels exceeded stem carbohydrate levels in both cultivars, although both sources were mobilized in temporally similar ways. In many perennial fruit crops, stem reserves are often mobilized before those of roots (Hagidimitrious and Roper, 1994; Keller and Loescher, 1989; Roper et al., 1988) presumably because they are closest to the developing fruit. In fact, Roper et al. (1988) surmised that root carbohydrate reserves may not be important to fruit development in sweet cherry. Although contribution of root carbohydrate reserves to fruit development was not directly assessed in our study, the sharp decline in root reserves before and just after anthesis suggests that these reserves may supply carbohydrate to developing fruit. The fact that root carbohydrate reserves declined significantly in 'Climax' during the period leading up to vegetative budbreak (i.e., 28 DAA) supports this, since the developing flowers and fruit would be the primary sinks during this time. Alternatively, the decrease in root carbohydrate content may reflect increased root respiration in early spring due to increased root temperatures in containerized plants compared to field grown plants (Priestley, 1981).

Starch serves as the major carbohydrate reserve in blueberry, as observed for apple (Kandiah, 1979), peach (Stassen et al., 1981), walnut (Lacointe et al., 1993), and sweet cherry (Keller and Loescher, 1989). Root and stem starch contents in both blueberry cultivars were depleted to very low levels during spring growth initiation. The extent of starch depletion in blueberry was markedly greater than that observed in cranberry (Hagidimitriou and Roper, 1994) or walnut (Lacointe et al., 1993) roots and stems during spring growth but was similar to the extent of depletion observed in sweet cherry (Keller and Loescher, 1989), again probably reflecting the high demand for carbohydrate in deciduous crops with short fruit development periods. Starch depletion occurred to the same extent in both blueberry cultivars but not within the same time period. Starch levels in roots and stems of 
'Bonita' were depleted to very low levels between dormancy and anthesis, at which time vegetative budbreak occurred and soon thereafter, export of currently assimilated carbohydrate from leaves began (unpublished data). 'Climax' used the same amount of starch but over a longer time, since currently assimilated leaf carbohydrate was not available until after 28 DAA. This suggests that there was potentially more reserve carbohydrate use by reproductive growth of 'Bonita' compared to 'Climax' during the period leading up to anthesis. Most cell division in blueberry pericarp tissue occurs before anthesis (Cano-Medrano, 1994), at which time carbohydrate reserves are the only source available to support growth and metabolism. Thus, limitations in carbohydrate reserve use (i.e., source limitation) before anthesis may result in decreased cell division in the fruit and resultant sink limitation to fruit growth later in the season. Such a scenario could partially account for the decreased size of 'Climax' fruit, although we have no evidence that a carbohydrate limitation actually occurs.

The similar amounts of ${ }^{14} \mathrm{C}$ in flowers of these two cultivars at anthesis would appear to argue against the idea that there was a difference in reserve carbohydrate use between the two cultivars before anthesis. This would be true if the carbohydrate reserve pools within and between the cultivars were homogeneously labeled. However, with nonhomogeneous labeling of pools (as likely occurred with our labeling protocol), direct comparison of ${ }^{14} \mathrm{C}$ content between cultivars is difficult, and comparison of starch contents in roots and stems between cultivars may be a more direct approach to determining reserve use.

The rapid decline in ${ }^{14} \mathrm{C}$ concentration of flowers and fruit and spring shoot growth for both cultivars, despite the increase in total

${ }^{14} \mathrm{C}$ accumulation in these organs throughout the fruit development period, suggests that there is substantially greater incorporation of current (unlabeled) assimilates compared to reserve (labeled) assimilates. Although fruit, to a limited extent, and new shoot growth, to a greater extent, continued to import reserve assimilates during fruit development, the quantities were apparently much less than quantities of current assimilates. This clearly appears to be the case for 'Climax', in which total ${ }^{14} \mathrm{C}$ accumulation in fruit and new shoot growth increased throughout fruit development. The situation in 'Bonita' is less clear because there was a sharp decline in total ${ }^{14} \mathrm{C}$ accumulation in fruit between 51 and $78 \mathrm{DAA}$. Although preferential respiration of stored carbohydrate vs. recently assimilated carbohydrate would explain the decline, respiration in the light is sustained primarily by recently assimilated carbohydrate (Ludwig and Canvin, 1971). Thus, the reason for this sharp decline is unknown.

The faster decline in ${ }^{14} \mathrm{C}$ concentration of 'Bonita' fruit compared to 'Climax' fruit between anthesis and 51 DAA (the beginning of stage III of fruit growth) indicates earlier incorporation of current assimilate into 'Bonita' fruit compared to 'Climax' fruit. Substantial amounts of current assimilates become available to 'Bonita' fruit by the middle of stage I, which occurs $\approx 20$ to 25 DAA (Birkhold et al., 1992), while current assimilates become available to 'Climax' fruit only after stage I of fruit development. This early supply of current carbohydrate, particularly between 28 and 51 DAA, may allow 'Bonita' fruit to develop at a faster rate than 'Climax' fruit and also may partially account for the increased fruit size in 'Bonita'.

In our study, patterns of root and stem starch depletion suggest that there is potentially greater use of starch reserves by developing flowers of 'Bonita' compared to 'Climax' during the pre-anthesis stage. Additionally, the delay in vegetative budbreak in 'Climax' compared to 'Bonita' would delay the availability of current photosynthate to fruit growth. Both of these factors may contribute to fruit size differences observed in these two cultivars. Thus, factors that decrease reserve accumulation, such as premature leaf abscission, or factors that delay or reduce early leaf development, such as insufficient chilling, may be expected to decrease fruit yield in blueberry.

\section{Literature Cited}

Birkhold, K.B., K.E., Koch, and R.L. Darnell. 1992. Carbon and nitrogen economy of developing rabbiteye blueberry fruit. J. Amer. Soc. Hort. Sci 117:139-145.

Cano-Medrano, R. 1994. Pollination and GA effects on fruit growth, sucrose metabolism, cell number, and cell size of blueberry fruits. $\mathrm{PhD}$ Diss. Horticultural Sciences Dept., Univ. of Florida, Gainesville.

Chaplin, M.F. and J.F. Kennedy. 1986. Carbohydrate analysis: A practical approach. IRL Press, Washington, D.C.

Darnell, R.L. 1991. Photoperiod, carbohydrate partitioning, and reproductive development in rabbiteye blueberry. J. Amer. Soc. Hort. Sci. 116:856-860.

Darnell, R.L. and F.S. Davies. 1990. Chilling accumulation, budbreak, and fruit set of young rabbiteye blueberry plants. HortScience 25:635-638.

Hagidimitriou, M. and T.R. Roper. 1994. Seasonal changes in nonstructural carbohydrate in cranberry. J. Amer. Soc. Hort. Sci 119:1029-1033.

Hansen, P. 1967. ${ }^{14} \mathrm{C}$-studies on apple trees. I. The effect of the fruit on the translocationand distribution of photosynthates. Physiol.Plant. 20:382-391.

Hansen, P. 1971. ${ }^{14} \mathrm{C}$-studies on apple trees. VII. The early seasonal growth in leaves, flowers and shoots as dependent upon current photosynthates and existing reserves. Physiol. Plant. 25:469-473.

Kandiah, S. 1979a. Turnover of carbohydrate in relation to growth in apple trees. 1. Seasonal variation of growth and carbohydrate reserves. Ann. Bot. 44:175-184.

Kandiah, S. 1979b. Turnover of carbohydrate in relation to growth in apple trees. 2. Distribution of ${ }^{14} \mathrm{C}$ assimilates labelled in autumn, spring, and summer. Ann. Bot. 44:185-195.

Keller, J.D. and W.H. Loescher. 1989. Nonstructural carbohydrate partitioning in perennial parts of sweet cherry. J. Amer. Soc. Hort. Sci. 114:969-975.

Lacointe, A., A. Kajji, F. Daudet, P. Archer, and J. Frossard. 1993. Mobilization of carbon reserves in young walnut trees. Acta Bot. Gallica 140:435-441.

Lockwood, D. and D. Sparks. 1978a. Translocation of ${ }^{14} \mathrm{C}$ in 'Stuart' pecan in the spring following assimilation of ${ }^{14} \mathrm{CO}_{2}$ during the previous growing season. J. Amer. Soc. Hort. Sci. 103:38-45.

Lockwood, D. and D. Sparks. 1978b. Translocation of ${ }^{14} \mathrm{C}$ from tops and roots of pecan in the spring following assimilation of ${ }^{14} \mathrm{CO}_{2}$ during the previous growing season. J. Amer. Soc. Hort. Sci 103:45-49.

Ludwig, L.J. and D.T. Canvin. 1971. An open gas-exchange system for the simultaneous measurement of the $\mathrm{CO}_{2}$ and ${ }^{14} \mathrm{CO}_{2}$ fluxes from leaves. Can. J. Bot. 49:1299-1313.

Oliveira, C.M. and C.A. Priestley. 1988. Carbohydrate reserves in deciduous fruit trees. Hort. Rev. 10:403-430.

Priestley, C.A. 1981. Perennation in woody fruit plants and its relationship to carbohydrate turnover. Ann. Appl. Biol. 98:548-552.

Quinlan, J.D., 1969. Mobilization of ${ }^{14} \mathrm{C}$ in the spring following autumn assimilation of ${ }^{14} \mathrm{CO}_{2}$ by an apple rootstock. J. Hort. Sci. 44:107-110.

Quinlan, J.D. and A.P. Preston. 1968. Effects of thinning blossom and fruitlets on growth and cropping of 'Sunset' apple. J. Hort. Sci. 43:373-381.

Roper, T.R., J.D. Keller, W.H. Loescher, and C.R. Rom. 1988. Photosynthesis and carbohydrate partitioning in sweet cherry: Fruiting effects. Physiol. Plant. 72:42-47.

Stassen, P.J., D.K. Strydom, and H.W. Stindt. 1981. Seasonal changes in carbohydrate fractions of young 'Kakamas' peach trees. Agroplante 13:47-53.

Wardlaw, I.F. 1990. The control of carbon partitioning in plants. New Phytol. 116:341-381. 